\title{
Radicular Cyst: A Case Report
}

\author{
Raghu Kumaravelu ${ }^{1}$, Nithin J Jude ${ }^{2}$, R Sathyanarayanan ${ }^{3}$
}

\begin{abstract}
We are presenting a case of a 34-year-old female patient with a diagnosis of radicular cyst reported to Oral and Maxillofacial Surgery Department with a complaint of swelling in her face in relation to the right lower back tooth region for the past 1 month. Proved as a radicular cyst based on histopathology report after excision biopsy. In this case report, we focus on various diagnostic aspects of this cyst and its surgical management. The treatment of choice for this case was decompression followed by enucleation under local anesthesia. No recurrence was noted during the review.
\end{abstract}

Keywords: Decompression, Odontogenic cyst, Periapical cyst, Radicular cyst of mandibular, Surgical enucleation.

Journal of Scientific Dentistry (2021): 10.5005/jp-journals-10083-0939

\section{INTRODUCTION}

Radicular cyst in literature has been given multiple names according to its position, such as periapical cyst, root end cyst, apical periodontal cyst, or dental cyst. This originates as a result of inflammation due to pulpal necrosis or microtrauma from the epithelial cell rest of Malassez in the periodontal ligament. A radicular cyst is usually left unnoticed because of its asymptomatic nature unless it is been detected incidentally by radiographs. It clinically exhibits an enlargement at the site of infection. At first, the enlargement is usually bony hard, which later becomes fluctuant when the cyst has eroded the bone completely.

Definitive diagnosis will be planned according to clinical, radiographic, and histological evaluation. Marsupialization is always the preferred surgical option for a radicular cyst. In this article, we are presenting a case report on a radicular cyst that has been reported in our department of Maxillofacial Surgery, IGIDS (Fig. 1).

\section{Case Description}

A female patient aged 34 reported Oral and Maxillofacial surgery OPD, IGIDS with a presenting complaint of swelling of face in relation to lower right back tooth region for the past 1 month. The swelling
${ }^{1}$ Department of Oral and Maxillofacial Surgery, Indira Gandhi Institute of Dental Science, Sri Balaji Vidyapeeth, Puducherry, India

${ }^{2,3}$ Department of Oral Surgery, Indira Gandhi Institute of Dental Sciences, Sri Balaji Vidyapeeth, Puducherry, India

Corresponding Author: Raghu Kumaravelu, Department of Oral and Maxillofacial Surgery, Indira Gandhi Institute of Dental Science, Sri Balaji Vidyapeeth, Puducherry, India, Phone: +91 9043328474, e-mail: dr.raghuk@gmail.com

How to cite this article: Kumaravelu R, Jude NJ, Sathyanarayanan R. Radicular Cyst: A Case Report. J Sci Dent 2021;11(1):23-25.

Source of support: Nil

Conflict of interest: None

was small in size initially and it progressed gradually to the present size (Fig. 1). Patient gives a medical history of generalized body ache and she was under self-medication.

On extraoral examination, a swelling was noted on the right side lower one-third region of the face measuring about $4 \times 3$ $\mathrm{cm}$ extending inferiorly till the lower border of the mandible. The external surface overlying the swelling appeared normal with no secondary changes.
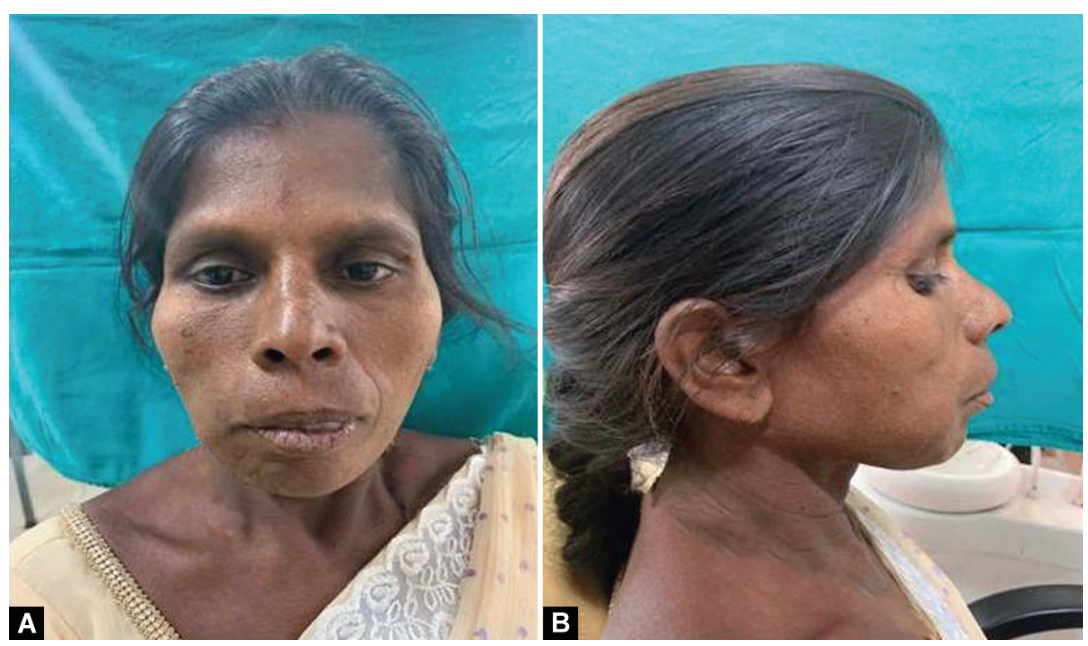

Figs $1 \mathrm{~A}$ and B: Profile picture: (A) Frontal view; (B) Lateral view

(0) The Author(s). 2021 Open Access This article is distributed under the terms of the Creative Commons Attribution 4.0 International License (https:// creativecommons.org/licenses/by-nc/4.0/), which permits unrestricted use, distribution, and non-commercial reproduction in any medium, provided you give appropriate credit to the original author(s) and the source, provide a link to the Creative Commons license, and indicate if changes were made. The Creative Commons Public Domain Dedication waiver (http://creativecommons.org/publicdomain/zero/1.0/) applies to the data made available in this article, unless otherwise stated. 

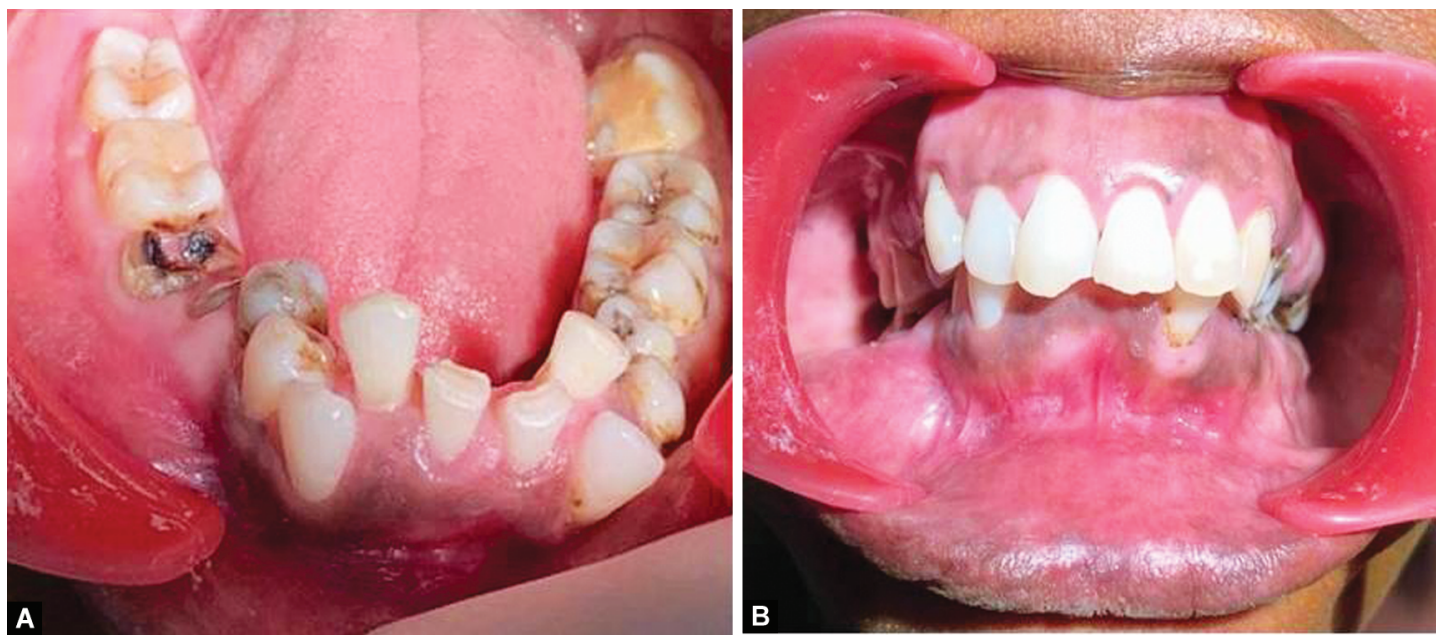

Figs $2 \mathrm{~A}$ and $\mathrm{B}$ : Intraoral view

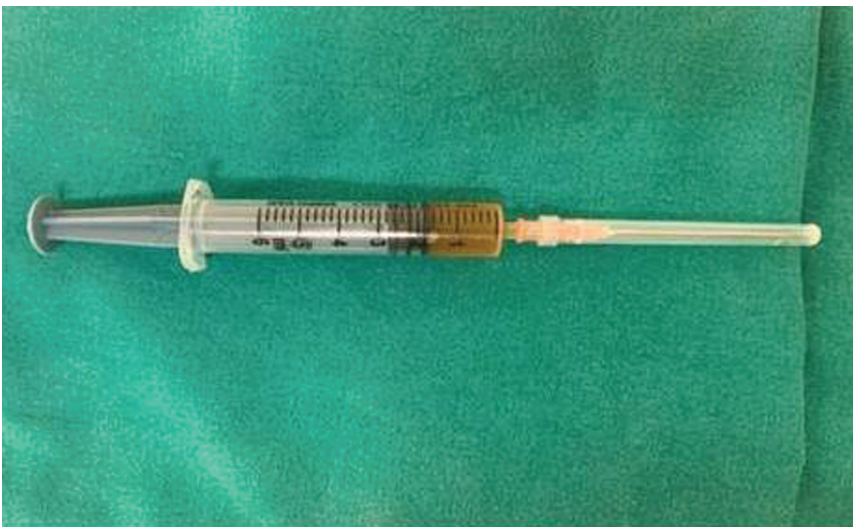

Fig. 3: FNAC

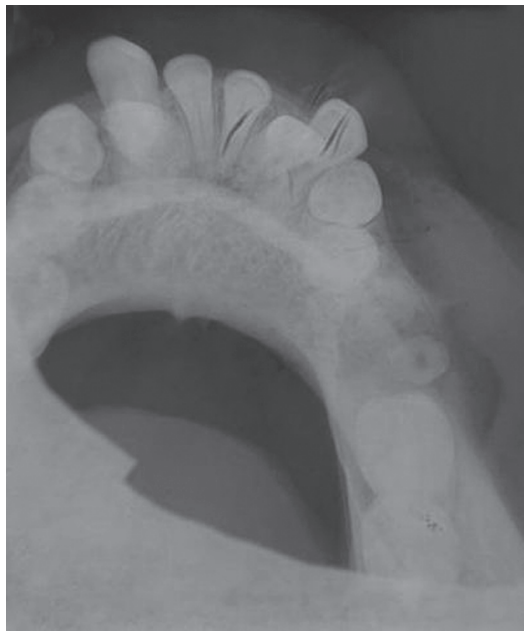

Fig. 5: Occlusal radiogragh

On palpation, it was non-mobile, no fixity, no pus discharge, soft, smooth, non-indurated, and non-tender.

On intraoral examination, there was a swelling obliterating the vestibule on the right mandibular posterior region in relation to 45, 46, 47 region (Fig. 2) no lingual bone expansion. On palpation, the swelling was a smooth border, reddish pink, soft consistency in relation to 45 and 47.

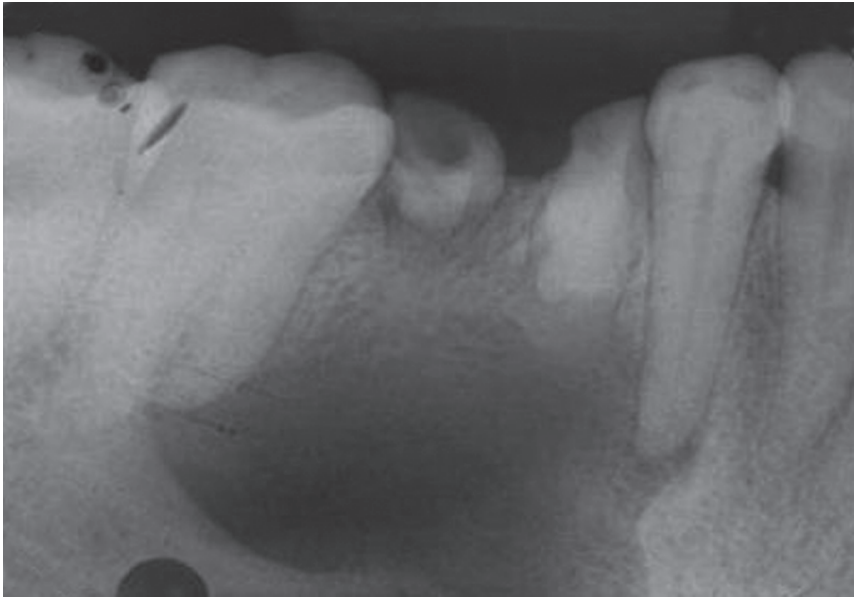

Fig. 4: IOPA

Fine needle aspiration cytology was performed which revealed pale yellow liquid. We provisionally diagnosed it as a radicular cyst of the right mandibular region based on the above clinical findings (Fig. 3).

The intraoral periapical radiograph showed well-defined unilocular radio-opacity line with a sclerotic border running and surrounding between apices of 45, 46, 47 (Fig. 4). On an occlusal radiograph, buccal expansion of cortical bone in relation to 45,46 , 47 (Fig. 5). Histological examination was done following incisional biopsy.

Histopathological examination reported as stratified squamous epithelial lining. The lining epithelium in one of the sections exhibits hyperplasia and focal area the epithelium is of two to three cell thicknesses. Area of mucous cells and ciliated changes are also seen, probably due to metaplastic changes. Apart from this, eosinophilic homogenized refractile material resembling hyaline bodies is also seen. The underlying connective tissue shows edematous changes with chronic inflammatory cell infiltrate (Fig. 6).

\section{Discussion}

A periapical cyst is also known as radicular cysts usually associated with a carious, non-vital, discolored, or fractured tooth. ' Stimulation of cell rest of Malassez, which are found in the periodontal membrane due to trauma or pulp necrosis, also contributes to the 

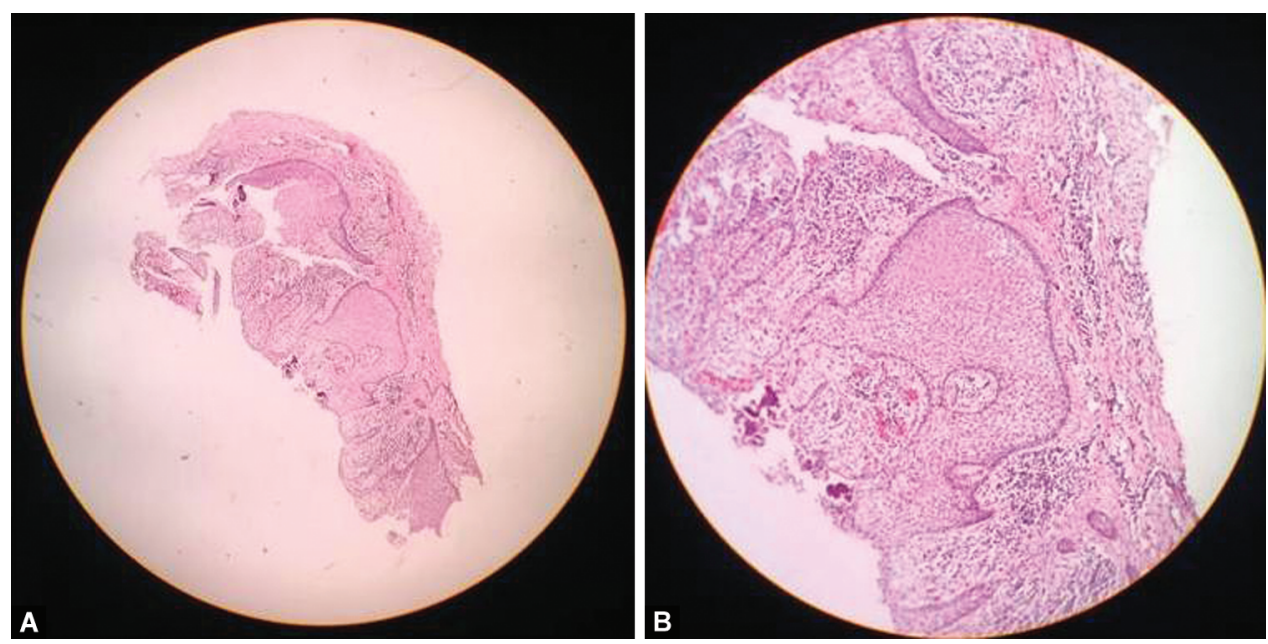

Figs $6 \mathrm{~A}$ and $\mathrm{B}$ : Histopath image

epithelial formation of the cyst. ${ }^{2}$ In literature, radicular cyst is most common among all the cysts of jawbones comprising about $50-70 \%$ of all cyst affecting bones of the human jaw. ${ }^{3}$

The radicular cyst can be seen in between 30th and 50th aged group peoples and male sex prominent relatively affecting the maxillary anterior regions. They are asymptomatic and slowgrowing bony swelling. In our case, it presented unilaterally in the mandibular region.

The pathophysiology of radicular cyst has three definitive phases; phase of initiation, cyst formation, enlargement. ${ }^{4}$ Radicular cyst are detected by radiography, but long-standing cases will have a typical character of the cystic lesion with acute exacerbation which can develop signs and symptoms such as swelling, displacement of an unerupted tooth, tooth mobility, root resorption of the affected tooth. Cases which is in advanced stages of bone resorption and cortical enlargement exhibits eggshell cracking. ${ }^{5}$

In the present case, there was the obliteration of vestibule on right posterior teeth region and in radiograph buccal expansion of cortical bone and well-defined unilocular radiolucency with sclerotic border.

Nearly, all radicular cysts are lined by non-keratinized stratified squamous epithelium. The epithelial lining could be thriving and arcading with a severe inflammatory progression and comprising polymorphonuclear lymphocytes. ${ }^{6}$

In the current case, histopathological examination revealed a stratified squamous epithelial lining. The lining epithelium in one of the sections exhibits hyperplasia and focal area the epithelium is of two to three cell thicknesses. Area of mucous cells and ciliated changes are also seen, probably due to metaplastic changes. Apart from this, eosinophilic homogenized refractile material resembling hyaline bodies is also seen. The underlying connective tissue shows edematous changes with chronic inflammatory cell infiltrate.

The line of treatment often depends on multiple factors such as the location of the cyst, cystic wall integrity, and size and proximity of the cyst in relation to vital structures. ${ }^{7}$ Treatment options such as extraction of offending tooth, endodontic and surgical management, enucleation of the cyst with an initial resolution, and marsupialization followed by enucleation at later intervals. ${ }^{8}$ In the current case report, surgical enucleation was done in a single piece and peripheral osteotomy is done and bony spicules removed.

\section{Conclusion}

A radicular cyst is a common condition found in the oral cavity. This case report illustrates a unilateral representation of radicular cyst. Thus, this case report of the radicular cyst summarizes the clinical features, histological features, and radiological features and its treatment were performed.

\section{References}

1. Shafer HL. Textbook of pathology. 6th ed., Amsterdam: Elseier; 2006.

2. Lin LM, Huang GT, Rosenberg PA. Proliferation of ept cells rests, formation of apical cysts aber periapical wound healing. J Endod 2007;33(8):908-916. DOI: 10.1016/j.joen.2007.02.006.

3. Riachi F, Tabarani C. Effective management of large radicular cyst using surgical enucleation vs marsupialization. IAJD 2010;1:44-51.

4. Latto S, Shah AA, Jan MS, Qudir S, Ahmed I, Purra AR, et al. Radicular cyst. JK Sci 2009;11(4):187-190.

5. Weber AL, Kanela T, Scrivani SJ, Azizs A. Jaw: cyst, tumour and non tumourous lesions. In: Head and neck imaging Som PM, Curtin HD, ed. 4th ed., St. Louis, MO: Mosby; 2003. pp. 930-944.

6. Shansudeen SM, Selvakumar T, Uma Magesh DD, Srinivasa Prasad T, Nalin Kumar S. Raicular cyst - a case report with an overview on pathogenesis. Indian J Multidicip Dent 2012;3(4):45-51.

7. Uloopi K, Shivaji R, Vinay C, Pavitra, Shrutha S, Chandrasekhar R. Conservative management of large radicular cyst associated with nonvital primary teeth: a case series and literature review. Indian Soc Pedod Prev Dent 2015;33(1):53-56. DOI: 10.4103/0970-4388.149007.

8. Mihailova TL, Nikolov VL, Slavkov SV. Diagnostic imaging dentigerous cyst of mandible. JIMAB Ann Proc (Sci pap) 2008. book 2. pp. 8-10. 